\title{
O USO DA MADEIRA NAS REDUÇÕES JESUÍTICO-GUARANI DO RIO GRANDE DO SUL. 8 - MÍSULA DO ALPENDRE DO COLÉGIO DE SÃO LUIZ GONZAGA ${ }^{1}$
}

\author{
MARIA CRISTINA SCHULZE-HOFER ${ }^{2}$ JOSÉ NEWTON CARDOSO MARCHIORI ${ }^{3}$
}

\begin{abstract}
RESUMO
A madeira de uma mísula do alpendre do colégio de São Luiz Gonzaga, conservada no Museu das Missões (São Miguel das Missões, Rio Grande do Sul - Brasil), foi anatomicamente identificada como Handroanthus heptaphyllus (Vell.) Mattos, espécie lenhosa de notável resistência mecânica e alta durabilidade natural. Palavras-chave: Handroanthus heptaphyllus, Tabebuia heptaphylla, Ipê-roxo, Anatomia da Madeira, Arqueologia, Missões Jesuíticas, Rio Grande do Sul.
\end{abstract}

\section{SUMMARY}

[Wood utilization in the Jesuitic-Guarani Missions from Rio Grande do Sul state, Brazil. 8 - A supporting bracket from Saint Louis Gonzaga's college porch].

The supporting bracket wood of Saint Louis Gonzaga's college porch, housed at Missions' Museum (São Miguel das Missões, Rio Grande do Sul - Brazil), was anatomically identified as Handroanthus heptaphyllus (Vell.) Mattos, a wood species that is notable for its mechanical strength and decay resistance.

Key words: Handroanthus heptaphyllus, Tabebuia heptaphylla, Wood Anatomy, Archeology, Jesuitic Missions, Rio Grande do Sul state - Brazil.

\section{INTRODUÇÃO}

$\mathrm{Na}$ linguagem arquitetônica, chama-se de mísula aos ornatos salientes, presos à parede $\mathrm{e}$ que, estreitos na parte inferior, largos na superior, destinam-se a sustentar um arco de abóbada, cornija, púlpito, suporte para vaso, estátua, etc.

As mísulas do colégio jesuítico de São Luiz Gonzaga, demolido na primeira metade do século XX, mereceram desenho de Lucio Costa (Figura 1) e encontram-se, atualmente, no Museu das Missões (São Miguel das Missões, Rio Grande do Sul), integrados a seu acervo (Figura 2A). O presente estudo tem o objetivo

\footnotetext{
${ }^{1}$ Recebido em 12-11-2008 e aceito para publicação em 14-02-2009.

2 Arquiteta e urbanista, Dra., IPHAN - Instituto do Patrimônio Histórico e Artístico Nacional. schulzehofer@gmx.de

${ }^{3}$ Engenheiro Florestal, Dr., Professor Titular do Departamento de Ciências Florestais, Universidade Federal de Santa Maria, RS. Bolsista de Produtividade em Pesquisa, CNPq - Brasil. balduinia@mail.ufsm.br
}

de identificar anatomicamente a espécie de madeira utilizada em sua confecção, além de contribuir para o melhor conhecimento das técnicas construtivas neste singular período da história regional.

\section{MATERIAL E MÉTODOS}

As amostras utilizadas (Figura 2B,C) foram retiradas de uma das mísulas do alpendre do colégio de São Luiz Gonzaga, conservada no Museu das Missões (São Miguel das Missões, Rio Grande do Sul). O material coletado foi registrado em fichário, fotografado, acondicionado em envelope com identificação e enviado ao Laboratório de Anatomia da Madeira do Instituto Nacional de Pesquisas da Madeira, em Lohbrügge - Hamburgo (Alemanha), onde foram realizados os trabalhos de microtécnica e fotomicrografia. Os autores agradecem à Sra. Eda John, pela colaboração nestas tarefas.

Do material coletado foram preparados três corpos-de-prova, orientados para a obtenção de 


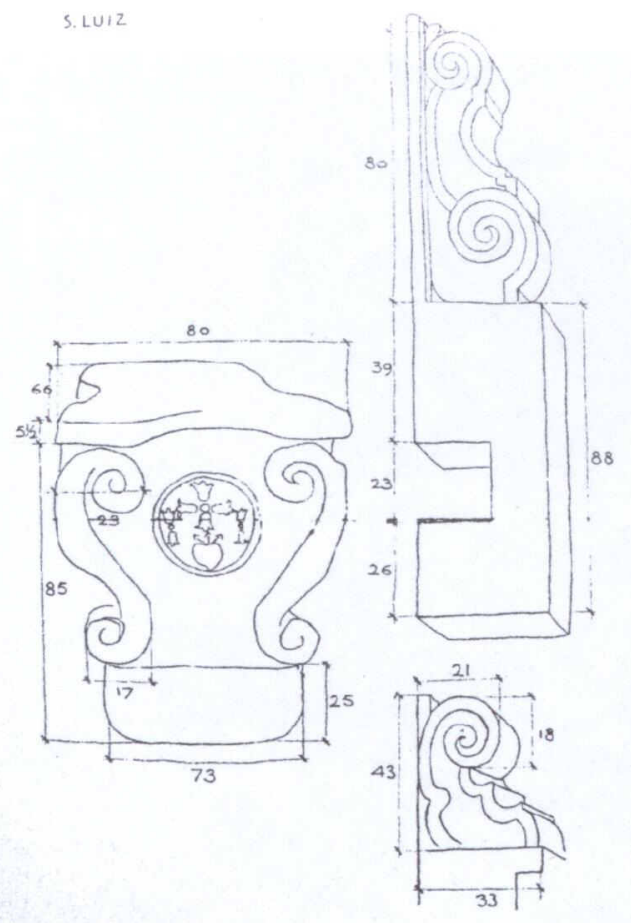

FIGURA 1 - Detalhe das mísulas do alpendre do extinto colégio jesuítico de São Luiz Gonzaga, em desenho do renomado arquiteto e urbanista Lucio Costa.

cortes anatômicos nos planos transversal, longitudinal radial e longitudinal tangencial. Os mesmos sofreram fervura em água, com vistas ao amolecimento e expulsão completa do ar, foram incluídos em PEG 2000 e seccionados em micrótomo de deslizamento (modelo American Optical), regulado para a obtenção de cortes anatômicos com espessura nominal de 20 $\mu \mathrm{m}$. No caso dos cortes radiais, parte deles foi tratada com hipoclorito de sódio, com vistas a salientar a eventual presença de cristais. As fotomicrografias da Figura 3 foram tomadas com câmera Olympus AX, em diferentes aumentos.

Para a identificação anatômica, serviu-se da literatura indicada na discussão e apresentada nas referências bibliográficas.

\section{DESCRIÇÃO ANATÔMICA}

Anéis de crescimento distintos, marcados, fracamente, pelo alinhamento de poros no início do anel (Figura 3A). Madeira de porosidade difusa (Figura 3A). Poros muito numerosos, arredondados ou ovais (Figura 3A, B); solitários e em múltiplos de poucas unidades (Figura 3A). Estratificação completa, incluindo elementos vasculares, parênquima axial, raios e fibras (Figura 3E, F).

Elementos vasculares retilíneos (Figura 3C, F), com placas de perfuração simples e abundante conteúdo amarelado na cavidade celular (Figura 3B). Espessamentos espiralados, ausentes. Pontoações intervasculares alternas, de 12 a $14 \mu \mathrm{m}$ de diâmetro, com aréola circular e abertura lenticular inclusa.

Parênquima vasicêntrico incompleto, tendente a confluente, sem formar, todavia, faixas concêntricas (Figura 3A, B). Séries parenquimáticas, geralmente com 2 células por série.

Raios homogêneos (Figura 3C, D) e em número de 5 a 10/mm (Figura 3E), compostos inteiramente de células procumbentes (Figura 3C, D). Raios com menos de 10 células de altura e geralmente trisseriados, menos comumente uni e multisseriados (Figura 3E, F).

Fibras libriformes, de paredes espessas a muito espessas (Figura 3B).

\section{ANÁLISE ANATÔMICA E DISCUSSÃO}

A presença de raios relativamente estreitos e baixos, de pontoações intervasculares não ornamentadas, bem como a porosidade difusa $\mathrm{e}$ a ausência de espessamentos espiralados em vasos, remetem a amostra à família Bignoniaceae, segundo chave dicotômica para madeiras americanas com estrutura estratificada (Record, 1943).

O parênquima vasicêntrico incompleto, tendente a confluente, bem como a porosidade difusa, a abundância de conteúdo amarelado nos vasos e os raios finos, com 3-4 (raro mais) células de largura, inserem a amostra no "grupo Lapacho" do gênero Tabebuia, de acordo com Record \& Hess (1940). Composto de numerosas espécies, distribuídas em vasta área geográfica, o referido grupo distingue-se das demais seções 

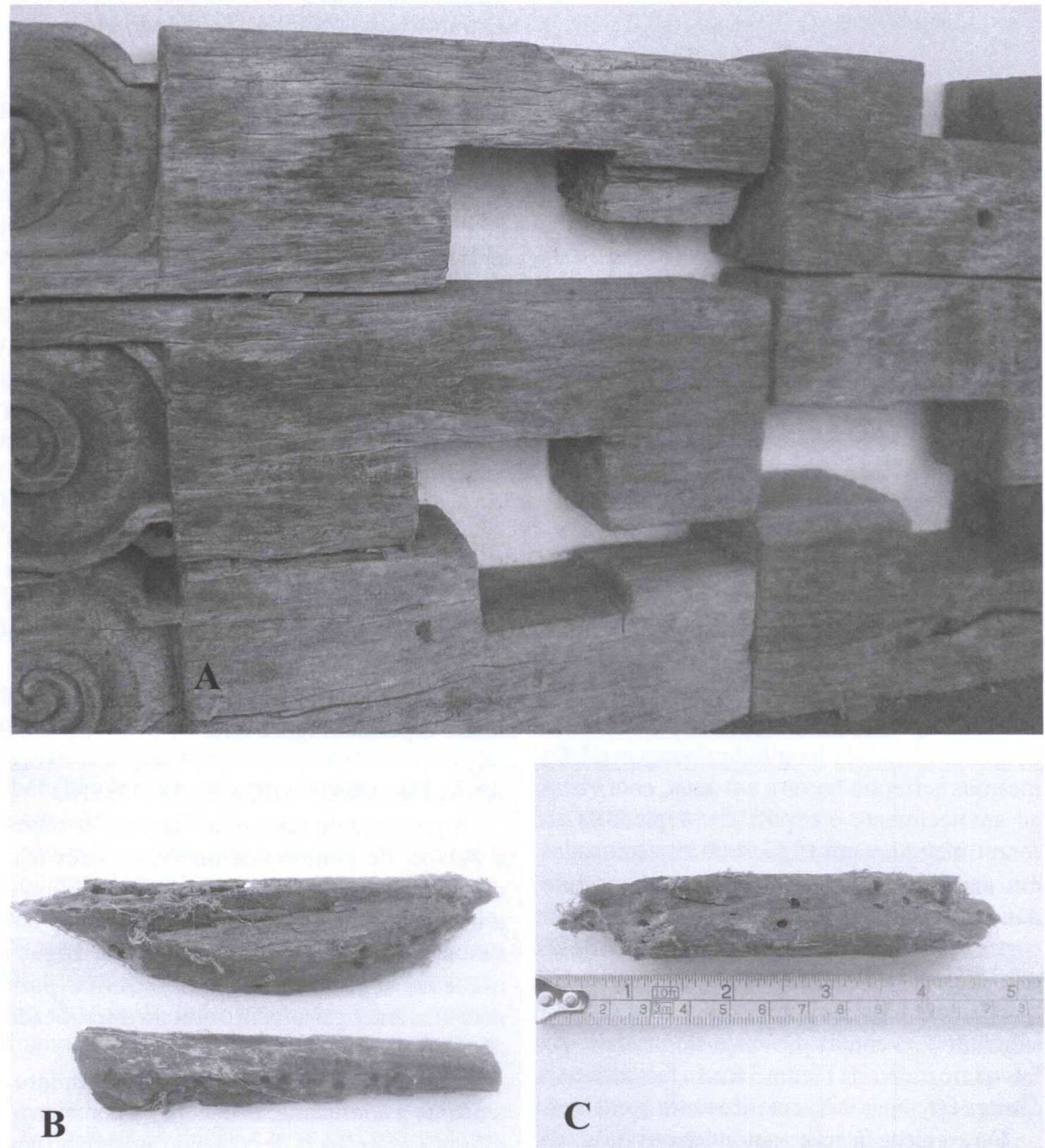

FIGURA 2 - Mísulas do alpendre do extinto colégio jesuítico de São Luiz Gonzaga. A - Vista parcial das peças, conservadas no Museu das Missões (São Miguel das Missões, Rio Grande do Sul). B, C - Amostras coletadas para estudos anatômicos. 

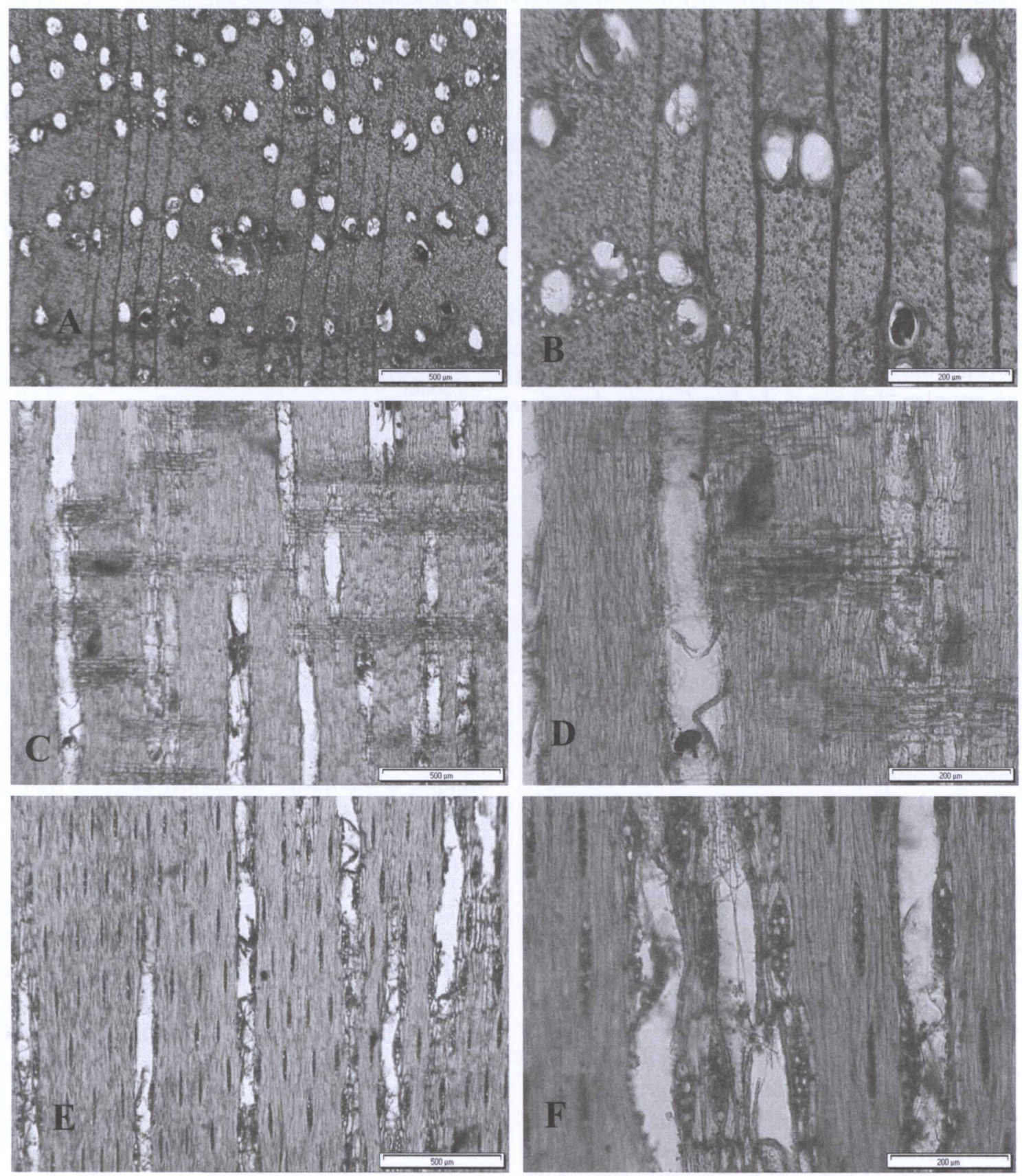

FIGURA 3 - Fotomicrografias da madeira. A-Anel de crescimento distinto, porosidade difusa e poros muito numerosos, em seção transversal. B - Poros ovais com abundante conteúdo, parênquima vasicêntrico incompleto e fibras de paredes espessas a muito espessas, em seção transversal. C - Raios homogêneos e linhas vasculares retilíneas, em seção radial. D - Raios compostos inteiramente de células procumbentes e fibras de paredes espessas a muito espessas, em seção radial. E - Linhas vasculares retilíneas e estratificação completa, em seção tangencial. F - Mesmos aspectos da imagem anterior, com maior aumento. 
de Tabebuia pela cor castanho-esverdeada da madeira, bem como pela presença de abundantes depósitos amarelados (Lapachol) em vasos do cerne (Record \& Hess, 1943).

O exame detalhado dos três cortes anatômicos, comparado a exemplares representados no Laminário do Departamento de Ciências Florestais da Universidade Federal de Santa Maria, permite identificar o material em estudo como Tabebuia heptaphylla (Vell.) Toledo, com base na presença de raios relativamente finos e no parênquima vasicêntrico incompleto, tendente a confluente, sem formar, todavia, faixas concêntricas. Atribuído ao popular "Ipê-roxo" do Rio Grande do Sul, este binômio latino foi reduzido, por Mattos (1970), à sinonímia de Handroanthus heptaphyllus, nome científico atualmente válido para a espécie (Lozano \& Zapater, 2008).

Abundante na região missioneira do Rio Grande do Sul, o ipê-roxo é árvore de grande porte, com troncos retos e diâmetro considerável em indivíduos adultos, produtora de madeira notável por sua durabilidade natural e elevada resistência mecânica. O uso do ipê, comprovado no presente estudo anatômico, demonstra que os construtores jesuítas conheciam - e muito bem - a matéria-prima disponível na região, por terem escolhido a madeira mais resistente $\mathrm{e}$ apropriada a obras externas, caso das mísulas do alpendre do extinto colégio jesuítico de São Luiz Gonzaga.

\section{REFERÊNCIAS BIBLIOGRÁFICAS}

LOZANO, E.C.; ZAPATER, M.A. Delimitación y estatus de Handroanthus heptaphyllus y $H$. impetiginosus (Bignoniceae, Tecomeae). Darwiniana, San Isidro, v. 46, n. 2, p. 304-317, 2008.

MATTOS, J.R. Handroanthus, um novo gênero para os "ipês" do Brasil. Loefgrenia, São Paulo, n. 50 , p. $1-4,1970$.

RECORD, S.J. Woods of storied structure. Tropical Woods, n. 76, p. 32-47, 1943.

RECORD, S.J.; HESS, R.W. American timbers of the family Bignoniaceae. Tropical Woods, n. 63, p. 9-38, 1940.

RECORD, S.J.; HESS, R.W. Timbers of the New World. New Haven: Yale University Press, 1943. $640 \mathrm{p}$. 